\title{
Morphology Control and Cycling Stability of Sn Nanostructures and Sn/RGO Composites as Lithium-Ion Battery Anodes
}

\author{
Yang Li, Jiawei Shi, Ying Liang*
}

Institute of Nuclear Technology and Application, School of Science, East China University of Science and Technology, Meilong Road 130, Shanghai 200237, China

*E-mail: yliang@ecust.edu.cn

doi: $10.20964 / 2018.03 .63$

Received: 8 November 2017 / Accepted: 13 January 2018 / Published: 5 February 2018

Crystalline tin ( $\mathrm{Sn}$ ) nanostructures and tin/reduced graphene oxide ( $\mathrm{Sn} / \mathrm{RGO})$ composites have been synthesized with different morphologies via a facile reduction method. The effects of the morphology and particle size on the cycling stability of $\mathrm{Sn}$ and $\mathrm{Sn} / \mathrm{RGO}$ as Li-ion battery anodes were investigated. For crystalline Sn, different morphologies of nanosheets, nanorods, nanospheres and nanoparticles were obtained by adjusting the reaction conditions, such as the reaction temperature and precursor. The associated electrodes exhibited a rapid capacity decay and weak cycling stability. However, smallsized Sn particles displayed a relatively more stable cycling performance than that of the larger-sized particles. Compared with $\mathrm{Sn}$, the cycling stability of the $\mathrm{Sn} / \mathrm{RGO}$ composites was greatly improved with a long cycling life, even at a larger current density. For instance, the Sn/RGO electrode, in which spherical Sn nanoparticles with diameters of $\sim 5 \mathrm{~nm}$ are uniformly dispersed on the RGO surface, delivers a reversible discharge capacity of $355 \mathrm{mAh} \mathrm{g}^{-1}$ at the end of 50 cycles at $200 \mathrm{~mA} \mathrm{~g}^{-1}$.

Keywords: Tin; reduced graphene oxide; nanostructures; Li-ion battery anodes

\section{$\underline{\text { FULL TEXT }}$}

(C) 2018 The Authors. Published by ESG (www.electrochemsci.org). This article is an open access article distributed under the terms and conditions of the Creative Commons Attribution license (http://creativecommons.org/licenses/by/4.0/). 